\title{
Development of a rapid and reliable high-performance liquid chromatography method for determination of water-soluble vitamins in veterinary feed premix
}

\author{
Md. Zahangir Hosain (D, S. M. Shariful Islam (iD and Md. Mostofa Kamal(D)
}

\author{
Quality Control Laboratory, Department of Livestock Services, Savar, Dhaka-1343, Bangladesh. \\ Corresponding author: Md. Zahangir Hosain, e-mail: zhosain79@gmail.com \\ Co-authors: SMSI: sharifdls1975@gmail.com, MMK: mostofa.kamal.phd@gmail.com \\ Received: 12-08-2021, Accepted: 01-11-2021, Published online: 08-12-2021
}

doi: www.doi.org/10.14202/vetworld.2021.3084-3090 How to cite this article: Hosain MZ, Islam SMS, Kamal MM (2021) Development of a rapid and reliable high-performance liquid chromatography method for determination of water-soluble vitamins in veterinary feed premix, Veterinary World, 14(12): 3084-3090.

\begin{abstract}
Background and Aim: Determination of trace amounts of vitamins in multi-component feed premix is a troublesome analytical procedure. In this study, a simple and rapid high-performance liquid chromatography (HPLC) method was developed and validated for the concurrent detection and quantitation of four water-soluble vitamins such as thiamine, riboflavin, pyridoxine, and cyanocobalamin in veterinary feed premixes.

Materials and Methods: The chromatographic separation of the vitamins was carried out at $35^{\circ} \mathrm{C}$ temperature on a reversed-phase $\mathrm{C} 18$ column using a gradient pump mode. Mobile phase constituents were solvent (a): 25 mM Potassium dihydrogen phosphate and $5 \mathrm{mM}$ sodium hexanesulfonate in deionized water having $\mathrm{pH}-4.0$ and solvent and (b) $5 \mathrm{mM}$ sodium hexanesulfonate in methanol. Detection was performed with HPLC ultraviolet/visible detection set at 278 and $361 \mathrm{~nm}$ wavelength in two different channels. The flow rate was $1.2 \mathrm{~mL} / \mathrm{min}$ and the total run time was $25 \mathrm{~min}$.

Results: The method was validated according to the International Conference on Harmonization and Food and Drug Administration guidelines and acceptance criteria for system suitability, precision, linearity, and recovery were met in all cases. The relative standard deviation for system suitability and precision was $<2 \%$ for all vitamins. The linearity of the calibration curves was excellent $\left(\mathrm{R}_{2}>0.999\right)$ at concentration of $5,10,15,20,25$, and $30 \mu \mathrm{g} / \mathrm{mL}$ for all vitamins. The limits of detection values were $0.0125,0.0017,0.0064$, and $0.0065 \mu \mathrm{g} / \mathrm{mL}$ for thiamine, riboflavin, pyridoxine, and cyanocobalamin, respectively, and the limits of quantification values were $0.0378,0.0051,0.0213$, and $0.0198 \mu \mathrm{g} / \mathrm{mL}$ for thiamine, riboflavin, pyridoxine, and cyanocobalamin, respectively. The recovery percentages ranged from $88 \%$ to $115 \%$.
\end{abstract}

Conclusion: The overall parameters of the proposed method met the validation criteria and this method could be a highly desirable technique for routine analysis of water-soluble vitamins in veterinary feed premix.

Keywords: method development, veterinary feed-premix, water-soluble vitamin.

\section{Introduction}

Vitamins are critical and biologically active organic compounds that are minor but essential constituents of food required for normal metabolism in human and animal bodies [1,2]. Feed premixes have been widely used in animal nutrition and the manufacture of a feed premix is a significant aspect of veterinary feed production [3]. Even the premixes are designed for the market or used directly for feed production; it is necessary to achieve homogeneity and well balanced of all ingredients. Different types and quantities of micro-ingredients such as vitamins have been used in feed premix production depending on species and categories of animals [4]. Nowadays, contemporary feed production is inconceivable without adding vitamin-mineral premixes. Although, a trace amount of vitamins is required

Copyright: Hosain, et al. Open Access. This article is distributed under the terms of the Creative Commons Attribution 4.0 International License (http://creativecommons.org/licenses/by/4.0/), which permits unrestricted use, distribution, and reproduction in any medium, provided you give appropriate credit to the original author(s) and the source, provide a link to the Creative Commons license, and indicate if changes were made. The Creative Commons Public Domain Dedication waiver (http://creativecommons.org/ publicdomain/zero/1.0/) applies to the data made available in this article, unless otherwise stated. in the diet they are considered essential and their effects on animal performance are vast [5]. There are two groups of vitamins, namely, water-soluble vitamins and fat-soluble vitamins [6]. Water-soluble vitamins such as thiamine, riboflavin, pyridoxine, and cyanocobalamin are involved in many biochemical pathways and help in energy metabolism [7]. However, they only are stored in small amounts and immediately lost with the flow of food or discharged with urine [8]. Therefore, the body needs a continuous supply of water-soluble vitamins to prevent deficiency symptoms and maintain normal body function.

Water-soluble vitamins have been extensively used as vitamin-mineral feed premix in animal production, especially in the poultry industry. The necessity of balanced vitamin-mineral premix in the poultry sector is increasing day by day to optimize the diet compositions and meet the demand of modern poultry production [9]. While vitamin plays a minimal part relative to complete nutrition, they have a key role in the welfare and performance of poultry, along with supporting crucial body functions such as growth performance, reproduction, and immunity [10]. Finished feed is incomplete without supplementation 
of vitamins and minerals, and it is very important to add a premix in poultry feed to achieve a sufficient level of vitamins and minerals and to prevent the birds from becoming malnourished [11]. They are also used for reducing diseases in animals and poultry [12]. Although the veterinary vitamin-mineral premixes are an important requirement for the rapid and sustainable growth of poultry and livestock production, the question raises about their standard and quality.

However, precise and routine analysis of water-soluble vitamins in veterinary feed premix is challenging due to the complex composition and unstable nature of the target analytes. Many factors can affect the stability of these vitamins such as heat, light, $\mathrm{pH}$, air as well as interactions with other feed components $[13,14]$. Furthermore, the extraction of these vitamins involves pretreatment through complex chemical reactions, and then a separate method to determine each vitamin. Therefore, the development of a validated analytical method to determine each component of water-soluble vitamins is comparatively a difficult analytical procedure. Some analytical methods such as ultraviolet/visible (UV/Vis) spectrophotometry, fluorimetry, chemiluminescence, capillary electrophoresis, thin-layer chromatography, and liquid chromatography have been offered for the determination of water-soluble vitamins $[15,16]$. Among these, high-performance liquid chromatography (HPLC) appears promising due to the advancement of both stationary phases and chromatography equipment [17].

The liquid chromatography technique has been widely applied for vitamin analysis from different matrices with some drawbacks such as low reproducibility, longer retention time, and complex mobile phases associated with longer column equilibration, and the total run time of the analysis upper to $60 \min [18,19]$. Due to the complex composition of the veterinary feed premix and the unstable nature of some vitamins, the extraction and analysis procedure is tedious and time-consuming; sometimes, a special preparation technique is required to obtain the analyte contained in the sample matrix [20]. For this reason, very few standards and validated methods are available for the quantification of water-soluble vitamins in veterinary feed premix.

Hence, the current study aimed to develop a simple, rapid, and validated HPLC technique for the determination of water-soluble vitamins such as thiamine $\left(\mathrm{B}_{1}\right)$, riboflavin $\left(\mathrm{B}_{2}\right)$, pyridoxine $\left(\mathrm{B}_{6}\right)$, and cyanocobalamin $\left(\mathrm{B}_{12}\right)$ in veterinary feed-premix.

\section{Materials and Methods}

\section{Ethical approval}

The present study did not need contact with animals. Hence, ethical approval did not require in this study.

\section{Study period and location}

The study was conducted from December 2019 to July 2021 in the Quality Control Laboratory,
Department of Livestock Services (DLS), Dhaka, Bangladesh.

\section{Chemicals and reagents}

Potassium dihydrogen phosphate $\left(\mathrm{KH}_{2} \mathrm{PO}_{4}\right)$, sodium hexanesulfonate, and methanol (HPLC grade) used in this study were purchased from Sigma-Aldrich and certified reference standard (CRS) of thiamine (Code: Y0000467, Batch: 2.3, ID: 003qpE), riboflavin (Code: R0600000, Batch: 5.0, ID: 007Auc), pyridoxine hydrochloride (Code: P4100000, Batch: 2.0, ID: 001UF1), and cyanocobalamin (Code: C3000000, Batch: 6.0, ID: 00EbaR) were purchased from Europian Pharmacopoeia Reference Standard, Council of Europe, EDQM CS 30026F-67081, Strasbourg, Cedex. Double deionized (DI) water used in this study was obtained from a water deionization plant (ePure-D4642-33, Thermo, USA). All solutions were sonicated and filtered through a $0.45 \mathrm{~mm}$ filter using a vacuum filtration unit (Welch, Pall Scientific, USA) before use.

\section{HPLC method}

The high-performance liquid chromatographic system (Waters alliance, Model-e2695XC separation module, 2489 UV/Vis Detector, Waters Corporation, USA) with a data processing unit Empower-3 software was used in this study. HPLC column Waters X-Bridge $(4.6 \times 150 \mathrm{~mm}), 5 \mu \mathrm{M}$ Packing $\mathrm{C} 18$ was used for the separation of vitamins. A gradient pump mode was used where $25 \mathrm{mM} \mathrm{KH_{2 }} \mathrm{PO}_{4}$ and $5 \mathrm{mM}$ sodium hexanesulfonate in water having $\mathrm{pH}-4.0$ adjusted with phosphoric acid was used as mobile phase-A and 5 $\mathrm{mM}$ sodium hexanesulfonate in methanol was used as mobile phase-B. The flow rate and injection volumes were $1.2 \mathrm{~mL} / \mathrm{min}$ and $20 \mu \mathrm{L}$, respectively, and the column temperature was maintained at $35^{\circ} \mathrm{C}$. Wavelength of detection was $278 \mathrm{~nm}$ (Channel-A) for thiamine, riboflavin, pyridoxine, and $361 \mathrm{~nm}$ (Channel-B) for cyanocobalamin. The whole chromatography was performed at ambient temperature.

\section{Preparation of standard solution}

Weighed accurately $10 \mathrm{mg}$ from each of thiamine, riboflavin, pyridoxine, and cyanocobalamin CRS and transferred into four $100 \mathrm{~mL}$ amber color volumetric flasks separately. Initially, $30 \mathrm{~mL}$ of DI water were added to each flask and the contents were shaken vigorously by a vortex mixer for $3 \mathrm{~min}$ and sonicated for $10 \mathrm{~min}$ in an ultrasonic bath. Then, the solutions were diluted to volume with DI water and mixed thoroughly by vortex mixer. These solutions were used as reference stock standard solutions and kept in a refrigerator for further use. Working standard solutions were prepared from stock standard solutions. Before injecting into the liquid chromatography system, the solutions were filtered through a $0.45 \mu \mathrm{m}$ polyvinylidene difluoride (PVDF) syringe filter.

\section{Preparation of sample solution}

The procedure of standard solution and sample preparation was almost the same. Briefly, $5.0 \mathrm{~g}$ of veterinary feed-premix enriched with 
thiamine, riboflavin, pyridoxine, and cyanocobalamin was accurately weighed and transferred into a $100 \mathrm{~mL}$ amber color volumetric flask. Initially, $30 \mathrm{~mL}$ of DI water were added to the flask and the contents were shaken vigorously by a vortex mixer for $3 \mathrm{~min}$ and sonicated for $10 \mathrm{~min}$ in an ultrasonic bath. Then, the content was diluted to volume with DI water and mixed thoroughly by a vortex mixer for $3 \mathrm{~min}$. Thereafter, the mixer was filtered with Whatman 1 Filter paper. Finally, the sample solution was transferred into the sample vial after filtering with a $0.45 \mu \mathrm{m}$ PVDF syringe filter for liquid chromatography.

\section{Method validation parameters}

Method validation of the present study was performed by measuring the basic parameters of the validation process such as system suitability, precision, linearity, limits of detection (LOD), limits of quantification (LOQ), and recovery. The validation parameters were evaluated using recommended guidelines of the International Conference on Harmonization (ICH) [21] and the United States Food and Drug Administration (FDA) [22,23].

\section{System suitability}

The system suitability was evaluated by six replicate analyses of a standard aqueous mixture of all vitamins. The acceptance limit of the different parameters for system suitability of the method is calculated according to the guidelines of ICH and FDA where the acceptance criteria are the percentage of relative standard deviation (RSD) for retention time and peak area (PA) is $<2 \%$, the number of theoretical plates (TP) more than 2000 , tailing factor (TF), and peak resolution (RS) $>2$.

\section{Precision}

The precision of the method was evaluated based on repeatability and intermediate precision. The repeatability was calculated on the results obtained from the same day for six independent mixer solutions of the same concentration $(10 \mu \mathrm{g} / \mathrm{mL})$ and the intermediate precision was evaluated by calculating the repeatability of the same concentration $(10 \mu \mathrm{g} /$ $\mathrm{mL}$ ) by two analysts on different days. The percentage of RSD was calculated for estimating the precision of this study.

\section{Linearity}

To evaluate the linearity, six standard mixtures of thiamine, riboflavin, pyridoxine, and cyanocobalamin were prepared and a linear equation was established for each vitamin by plotting the PAs versus the concentrations. Three calibration curves were obtained on three consecutive days with a specified standard concentration of each vitamin. Linearity was calculated by running six standard mixtures of each vitamin, at final concentrations of $5,10,15,20$, 25 , and $30 \mu \mathrm{g} / \mathrm{mL}$.

\section{$L O D$ and $L O Q$}

The lowest qualitative and quantitative concentrations for the tested linearity range were calculated for each vitamin according to the guidelines of ICH2000. Both LOD and LOQ were calculated using the expression: $\mathrm{k} \times \mathrm{S} . \mathrm{D} / \mathrm{b}$, where $\mathrm{k}=3.3$ for the $\mathrm{LOD}$ and 10 for the LOQ, S.D=The standard deviation of the intercept, and $b=$ Slope of the calibration curve tested for linearity.

\section{Recovery}

The recovery studies were carried out by spiking different amounts $(80 \%, 100 \%$, and $120 \%)$ of each vitamin in the pre-analyzed formulation blank matrix sample along with the linearity range. For the estimation of recovery, an accurate amount of each vitamin at three concentration levels $(8,10$, and $12 \mu \mathrm{g} / \mathrm{g})$ was added to approximately $1.0 \mathrm{~g}$ of blank matrix powder, and then the powder was extracted and analyzed for recovery using the formula: recovery $(\%)=($ amount obtained/amount spiked) $\times 100$.

\section{Statistical analysis}

Data collected in this study were analyzed using Statistical Package for the Social Sciences version 16 statistical package by one-way analysis of variance and by independent samples Student's t-test. Linear regression analysis was performed using the least square method.

\section{Results and Discussion}

This study demonstrates the development and validation of a precise analytical method where the validation criteria [21-23] met in all cases. Representative chromatograms of standard solution and a real feed premix sample are depicted in Figure-1a and $b$, respectively. The elution of water-soluble vitamins through the analytical column occurs in a specific order and in groups that depend on their chemical properties [24]. As expected, polar vitamins (pyridoxine and thiamine) elute first, followed by low-polar vitamins (cyanocobalamin and riboflavin). The retention time of these four water-soluble vitamins was as follows: $9.34 \pm 0.01 \mathrm{~min}$ (pyridoxine), $12.55 \pm 0.01 \mathrm{~min}$ (thiamine), $13.16 \pm 0.01 \mathrm{~min}$ (cyanocobalamin), and $14.67 \pm 0.01 \mathrm{~min}$ (riboflavin).

The system suitability parameters (Table-1) reveal that the percentage of RSD for retention time and PA is $<2 \%$, the number of TP is more than 2000 , and TF and RS are $>2$, which prove that the values are within the specified limits of the validation process [21-23]. The precision for the method and analyst was evaluated that are shown in Tables-2 and 3. The results reveal that the RSD value for both cases is $<2 \%$, which indicates that the proposed method has good reproducibility. From the linearity of Figure- 2 and Table-4, it is found that all of the vitamins maintain excellent linearity $\left(\mathrm{R}^{2}>0.999\right)$ within 


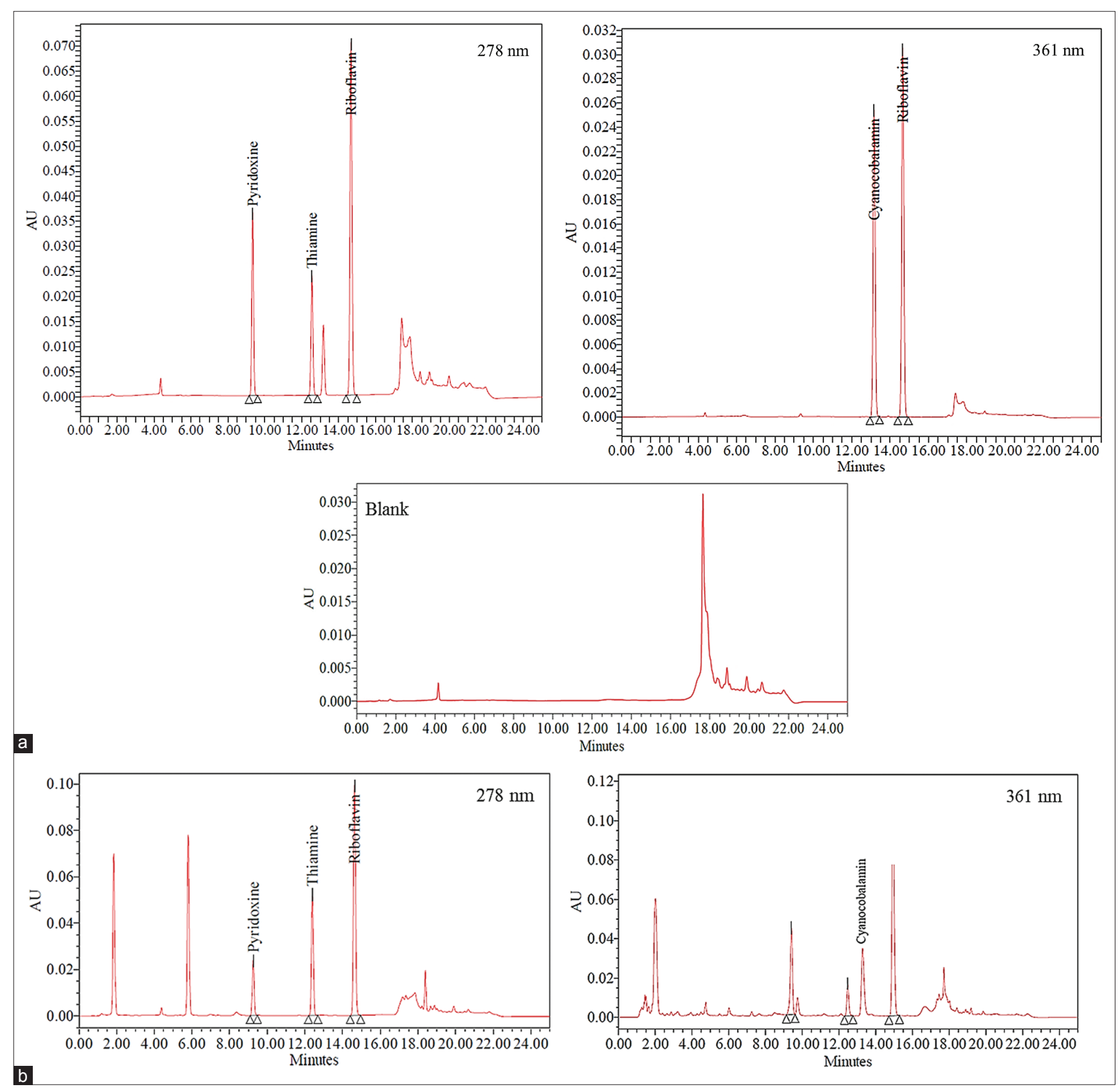

Figure-1: Typical chromatogram of vitamins mix analyzed under standardized conditions. (a) Chromatograms of thiamine, riboflavin, pyridoxine (at $278 \mathrm{~nm}$ ), and cyanocobalamin (at $361 \mathrm{~nm}$ ) mixed standard solution; (b) chromatograms of thiamine, riboflavin, pyridoxine (at $278 \mathrm{~nm}$ ), and cyanocobalamin (at $361 \mathrm{~nm}$ ) in sample solution of real veterinary feed premix.

Table-1: System suitability parameters of the proposed high-performance liquid chromatography method.

\begin{tabular}{lccccccc}
\hline Vitamin & RT $(\mathbf{m i n})$ & $\begin{array}{c}\text { \% RSD } \\
\text { of RT }\end{array}$ & Peak Area & $\begin{array}{c}\text { \% RSD of } \\
\text { Peak Area }\end{array}$ & $\begin{array}{c}\text { Theoretical } \\
\text { plates }\end{array}$ & Tailing factor & Resolution \\
\hline Thiamine $\left(\mathrm{B}_{1}\right)$ & $12.55 \pm 01$ & 0.11 & 175591 & 0.49 & 64177 & 1.04 & 17.18 \\
Riboflavin $\left(\mathrm{B}_{2}\right)$ & $14.67 \pm 01$ & 0.01 & 554275 & 0.22 & 77802 & 1.04 & 10.43 \\
Pyridoxine $\left(\mathrm{B}_{6}\right)$ & $9.34 \pm 01$ & 0.15 & 244745 & 0.22 & 43975 & 1.04 & - \\
Cyanocobalamin $\left(\mathrm{B}_{12}\right)$ & $13.16 \pm 01$ & 0.09 & 195841 & 0.42 & 6617 & 1.03 & 7.28 \\
\hline
\end{tabular}

$\mathrm{RT}=$ Retention time, $\mathrm{RSD}=$ Relative standard deviation

the concentration range of $5-30 \mu \mathrm{g} / \mathrm{mL}$. The lowest qualitative and quantitative concentrations for the tested linearity range were calculated for each vitamin. The LOD for thiamine, riboflavin, pyridoxine, and cyanocobalamin is found to be $0.0125,0.0017$,
0.0064 , and $0.0065 \mu \mathrm{g} / \mathrm{mL}$, respectively, and the LOQ for thiamine, riboflavin, pyridoxine, and cyanocobalamin is found to be $0.0378,0.0051,0.0213$, and $0.0198 \mu \mathrm{g} / \mathrm{mL}$, respectively, (Table-5). From the results shown in recovery Table- 6 , it is observed 
that the percentage recovery values of all the vitamins are between $88 \%$ and $115 \%$, which suggests that the method is accurate and it also indicates that the commonly used excipients and additives present in the feed premix formulations are not interfering

Table-2: Precision under repeatability conditions $(n=6)$.

\begin{tabular}{lcc}
\hline Vitamin & $\begin{array}{c}\text { Retention } \\
\text { time \% RSD }\end{array}$ & $\begin{array}{c}\text { Area } \\
\text { \% RSD }\end{array}$ \\
\hline Thiamine $\left(B_{1}\right)$ & 0.07 & 0.83 \\
Riboflavin $\left(B_{2}\right)$ & 0.07 & 0.47 \\
Pyridoxine $\left(B_{6}\right)$ & 0.08 & 0.63 \\
Cyanocobalamin $\left(B_{12}\right)$ & 0.08 & 0.39 \\
\hline
\end{tabular}

$\mathrm{RSD}=$ Relative standard deviation the proposed method. Many HPLC methods have been published concerning the simultaneous determination of vitamins, but most of the methods are not stable [25-27] which indicates the methods were not properly assessed during stability studies, and some of them are unable to quantify all the water-soluble vitamins simultaneously. Some stable methods were $[27,28]$ reported for the simultaneous quantification of seven water-soluble vitamins in multivitamin syrup preparations but they are unable to analyze cyanocobalamin. Few studies mention the methods of MS-MS detector [27,29], which involves specific and expensive equipment that is not available in all laboratories for routine analysis of these water-soluble

Table-3: Intermediate precision $(n=6)$.

\begin{tabular}{|c|c|c|c|c|}
\hline \multirow[t]{2}{*}{ Vitamin } & \multicolumn{2}{|c|}{ First analyst } & \multicolumn{2}{|c|}{ Second analyst } \\
\hline & Retention time \% RSD & Area \% RSD & Retention time \% RSD & Area \% RSD \\
\hline Thiamine $\left(\mathrm{B}_{1}\right)$ & 0.07 & 0.31 & 0.07 & 0.13 \\
\hline Riboflavin $\left(B_{2}\right)$ & 0.05 & 0.42 & 0.08 & 0.09 \\
\hline Pyridoxine $\left(\mathrm{B}_{6}\right)$ & 0.09 & 0.52 & 0.08 & 0.15 \\
\hline Cyanocobalamin $\left(\mathrm{B}_{12}\right)$ & 0.05 & 0.68 & 0.09 & 0.10 \\
\hline
\end{tabular}

$\mathrm{RSD}=$ Relative standard deviation

Table-4: Regression parameters of analyzed water-soluble vitamins (regression coefficient, $\mathrm{R}^{2}$ ) in calibration curves.

\begin{tabular}{lccc}
\hline Vitamin & \multicolumn{3}{c}{ Regression coefficient } \\
\cline { 2 - 4 } & $\mathbf{1}^{\text {st }}$ day & $\mathbf{2}^{\text {nd }}$ day & $\mathbf{3}^{\text {rd }}$ day \\
\hline Thiamine $\left(B_{1}\right)$ & $R^{2}=0.9993$ & $R^{2}=0.9993$ & $R^{2}=0.9993$ \\
Riboflavin $\left(B_{2}\right)$ & $R^{2}=0.9998$ & $R^{2}=0.9996$ & $R^{2}=0.9997$ \\
Pyridoxine $\left(B_{6}\right)$ & $R^{2}=0.9999$ & $R^{2}=0.9999$ & $R^{2}=0.9999$ \\
Cyanocobalamin $\left(B_{12}\right)$ & $R^{2}=0.9998$ & $R^{2}=0.9998$ & $R^{2}=0.9998$ \\
\hline
\end{tabular}
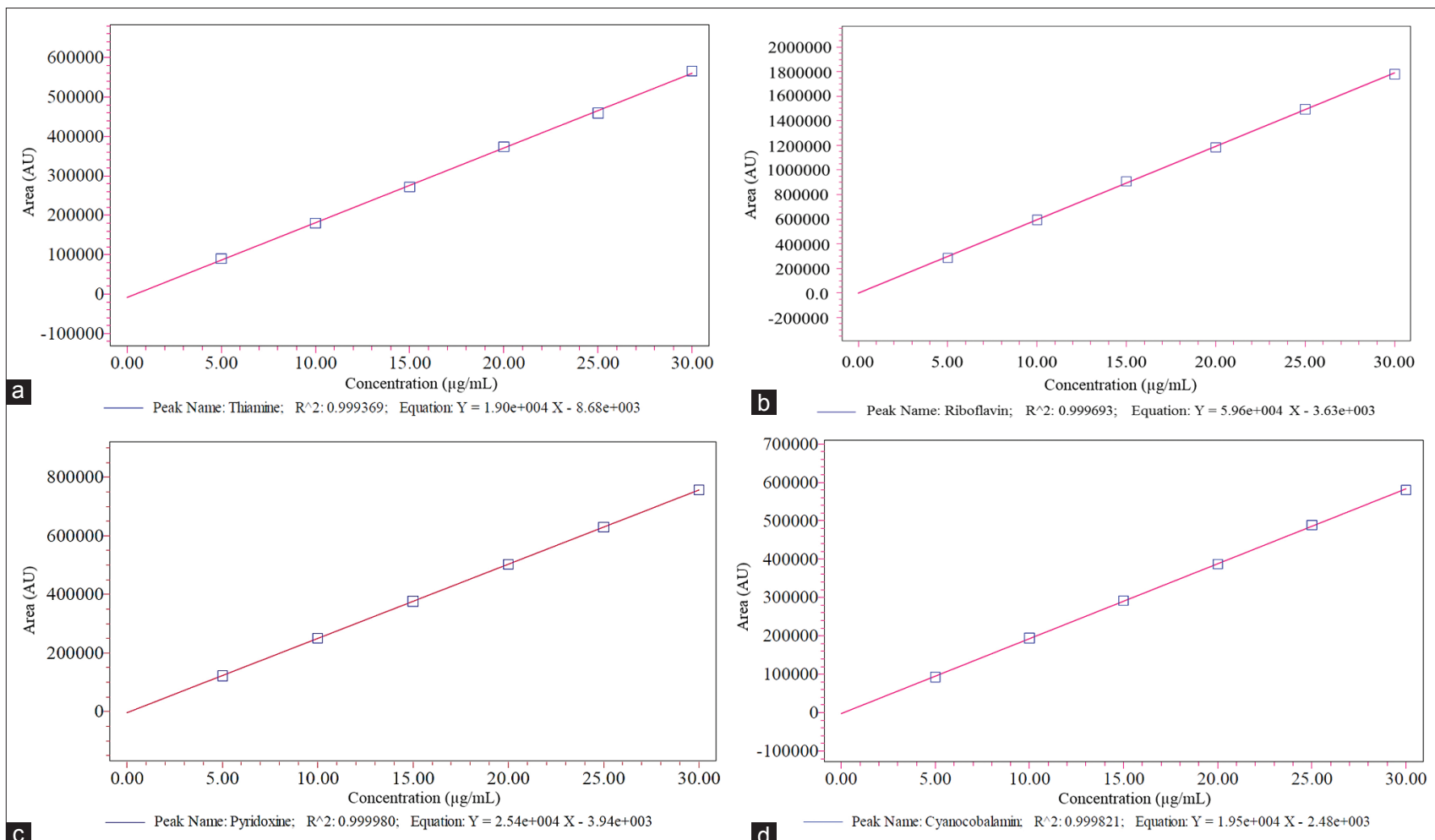

Figure-2: Calibration curve of (a) thiamine, (b) riboflavin, (c) pyridoxine, and (d) cyanocobalamin. 
Table-5: LOD and LOQ values of thiamine, riboflavin, pyridoxine, and cyanocobalamin.

\begin{tabular}{lcc}
\hline Vitamin & LOD $(\boldsymbol{\mu g} / \mathbf{m L})$ & LOQ $(\boldsymbol{\mu g} / \mathbf{m L})$ \\
\hline Thiamine $\left(B_{1}\right)$ & 0.0125 & 0.0378 \\
Riboflavin $\left(B_{2}\right)$ & 0.0017 & 0.0051 \\
Pyridoxine $\left(B_{6}\right)$ & 0.0064 & 0.0213 \\
Cyanocobalamin $\left(B_{12}\right)$ & 0.0065 & 0.0198 \\
\hline
\end{tabular}

LOD $=$ Limits of detection, $L O Q=$ Limits of quantification

Table-6: Recovery percentages of thiamine, riboflavin, pyridoxine and cyanocobalamin.

\begin{tabular}{|c|c|c|c|c|c|c|c|}
\hline \multirow[t]{2}{*}{ Vitamin } & \multirow{2}{*}{$\begin{array}{l}\text { Spike \% of the } \\
\text { vitamin }\end{array}$} & \multirow{2}{*}{$\begin{array}{l}\text { Spiked conc. } \\
(\mu g / g)\end{array}$} & \multicolumn{3}{|c|}{ Obtained conc. $(\mu \mathrm{g} / \mathrm{g})$} & \multirow{2}{*}{$\begin{array}{l}\text { Average obtained } \\
\text { conc. }(\mu \mathrm{g} / \mathrm{g})\end{array}$} & \multirow{2}{*}{$\begin{array}{l}\text { Average } \\
\text { recovery \% }\end{array}$} \\
\hline & & & $1^{\text {st }}$ Day & $2^{\text {nd }}$ Day & $3^{\text {rd }}$ Day & & \\
\hline \multirow{3}{*}{ Thiamine $\left(B_{1}\right)$} & 80 & 8 & 6.89 & 7.72 & 7.12 & 7.24 & 90.53 \\
\hline & 100 & 10 & 8.48 & 9.16 & 8.64 & 8.76 & 87.59 \\
\hline & 120 & 12 & 10.42 & 11.23 & 10.55 & 10.73 & 89.45 \\
\hline \multirow{3}{*}{ Riboflavin $\left(B_{2}\right)$} & 80 & 8 & 6.88 & 7.63 & 7.03 & 7.18 & 89.78 \\
\hline & 100 & 10 & 8.79 & 9.42 & 8.38 & 8.86 & 88.61 \\
\hline & 120 & 12 & 10.39 & 11.11 & 10.32 & 10.61 & 88.41 \\
\hline \multirow{3}{*}{ Pyridoxine $\left(B_{6}\right)$} & 80 & 8 & 8.44 & 9.21 & 9.98 & 9.21 & 115.10 \\
\hline & 100 & 10 & 10.41 & 9.20 & 12.07 & 10.56 & 105.60 \\
\hline & 120 & 12 & 13.01 & 9.22 & 14.52 & 12.25 & 102.08 \\
\hline \multirow{3}{*}{ Cyanocobalamin $\left(B_{12}\right)$} & 80 & 8 & 8.45 & 8.85 & 7.96 & 8.42 & 105.25 \\
\hline & 100 & 10 & 10.26 & 10.61 & 9.87 & 10.24 & 102.44 \\
\hline & 120 & 12 & 12.87 & 13.42 & 12.07 & 12.79 & 106.55 \\
\hline
\end{tabular}

vitamins. The method we developed is more precise with good repeatability, intermediate precision, reproducibility, and has high accuracy for detection of all the vitamins used in the study. The sample extraction procedure in our proposed method is simple and quantification of water-soluble vitamins in the real samples is also comparable to the declared values. Thus, the developed method is a simple and reliable approach for simultaneous detection and quantification of four water-soluble vitamins that have a wide range of applications in routine examination of veterinary feed premix.

\section{Conclusion}

In this study, a simple and precise analytical method is developed with an HPLC column for rapid and reliable analysis of water-soluble vitamins in complex veterinary feed premix. The simple technique for sample preparation and mobile phase containing water and methanol make the method more economical and desirable for the quantification of water-soluble vitamins in feed premixes. The recovery of each vitamin with the proposed procedure in the feed premix formulation is also high enough with their respective label claims. Therefore, this method could be a validated analytical procedure for accurate determination of water-soluble vitamins in multi-component veterinary feed premix and might be a precise technique to check the standard and quality of the feed premix intended to be used for increased livestock production.

\section{Authors' Contributions}

MZH: Conceptualized and designed the study. MZH and SMSI: Generated the data. MZH and SMSI: Analyzed the data. MZH: Drafted the manuscript.
MMK: Edited and finalized the manuscript. All authors read and approved the final manuscript.

\section{Acknowledgments}

The authors are thankful to the "Quality Control Laboratory for Livestock Inputs and its Food Products (QC Lab)" establishment project (No. 224071600) under the Department of Livestock Services, Government of Bangladesh, for providing the necessary funds for the study. We are grateful to Kazi Iqbal Mahmud Sonet and Md. Anwar Hossain, Analytical Division, Technoworth Associates Ltd., Bangladesh, for their technical support. We also thank Dr. Habiba Margia Khanam, Genesis Medical Clinic, Calgary, Alberta, Canada, for editing a draft of this manuscript.

\section{Competing Interests}

The authors declare that they have no competing interests.

\section{Publisher's Note}

Veterinary World remains neutral with regard to jurisdictional claims in published institutional affiliation.

\section{References}

1. Poongothai, S., Ilavarasan, R. and Karrunakaran, C. (2010) Simultaneous and accurate determination of Vitamins B1, B6, B12 and alpha-lipoic acid in multivitamin capsule by reverse-phase high performance liquid chromatographic method. Int. J. Pharm. Pharm. Sci., 2(4): 133-139.

2. Kennedy, D.O. (2016) B Vitamins and the brain: Mechanisms, dose and efficacy-a review. Nutrients, 8(2): 68 .

3. Rubaj, J., Korol, W. and Bielecka, G. (2012) Using High Performance Liquid Chromatography (HPLC) for Analyzing Feed Additives. Chromatography-the Most Versatile Method of Chemical Analysis. p165. 
4. Đuragić, O., Lević, J., Sredanović, S., Ivanov, D. and Kokić, B. (2009) Importance of carrier for feed premixes production. PTEP, 13(4): 324-327.

5. Tian, J.Z., Lee, J.H., Kim, J.D., Han, Y.K., Park, K.M. and Han, I.K. (2001) Effects of different levels of Vitaminmineral premixes on growth performance, nutrient digestibility, carcass characteristics and meat quality of growing-finishing pigs. Asian-Aust. J. Anim. Sci., 14(4): 515-524.

6. Lykstad, J. and Sharma, S. (2019) Biochemistry, Water Soluble Vitamins. StatPearls Publishing, Treasure Island (FL), PMID: 30860745.

7. Kienen, V., Costa, W.F., Visentainer, J.V., Souza, N.E. and Oliveira, C.C. (2008) Development of a green chromatographic method for determination of fat-soluble vitamins in food and pharmaceutical supplement. Talanta, 75(1): 141-146.

8. Almatsier, S. (2004) Prinsip Dasar Ilmu Gizi, Jakarta, Penerbit PT. Jakarta, Indonesia: Gramedia Pustaka Utama.

9. Ogunwole, O.A. and Mosuro, A.O. (2020) Dietary vitamin-mineral premix replacement with leaf meal composites improved the growth performance of broiler chicken. Slovak J. Anim. Sci., 53(3): 110-121.

10. Nakos, M., Pepelanova, I., Beutel, S., Krings, U., Berger, R.G. and Scheper, T. (2017) Isolation and analysis of Vitamin B12 from plant samples. Food Chem., 216(3): 301-308.

11. Alagawany, M., Elnesr, S.S., Farag, M.R., Tiwari, R., Yatoo, M.I., Karthik, K. and Dhama, K. (2021) Nutritional significance of amino acids, vitamins and minerals as nutraceuticals in poultry production and health-a comprehensive review. Vet. Q., 41(1): 1-29.

12. Yoshii, K., Hosomi, K., Sawane, K. and Kunisawa, J. (2019) Metabolism of dietary and microbial Vitamin B family in the regulation of host immunity. Front. Nutr., 6: 48.

13. Cellar, N.A., McClure, S.C., Salvati, L.M. and Reddy, T.M. (2016) A new sample preparation and separation combination for precise, accurate, rapid, and simultaneous determination of Vitamins B1, B2, B3, B5, B6, B7, and B9 in infant formula and related nutritional by LC-MS/MS. Anal. Chim. Acta., 934(33): 180-185.

14. Schmidt, A., Pratsch, H., Schreiner, M.G. and Mayer, H.K. (2017) Determination of the native forms of Vitamin B1 in bovine milk using a fast and simplified UHPLC method. Food Chem., 229(16): 452-457.

15. Arbatskii, A., Afon'shin, G. and Vostokov, V. (2004) Determination of vitamins in feed and foodstuffs by high-performance liquid chromatography. J. Anal. Chem., 59(12): 1186-1189.

16. Rudenko, A. and Kartsova, L. (2010) Determination of water-soluble Vitamin B and Vitamin C in combined feed, premixes, and biologically active supplements by reversedphase HPLC. J. Anal. Chem., 65(1): 71-76.

17. Moreno, P. and Salvado, V. (2000) Determination of eight water-and fat-soluble vitamins in multi-vitamin pharmaceutical formulations by high-performance liquid chromatography. J. Chromatogr. A, 870(1-2): 207-215.

18. Perveen, S., Yasmina, A. and Mohammed Khan, K. (2009) Quantitative simultaneous estimation of water soluble vitamins, riboflavin, pyridoxine, cyanocobalamin and folic acid in nutraceutical products by HPLC. Open Anal. Chem. $J ., 3(1): 1-5$.

19. Sasaki, K., Hatate, H. and Tanaka, R. (2020) Determination of 13 Vitamin B and the related compounds using HPLC with UV detection and application to food supplements. Chromatographia, 83(7): 839-851.

20. Klejdus, B., Petrlová, J., Potěšil, D., Adam, V., Mikelová, R., Vacek, J. and Kubáň, V. (2004) Simultaneous determination of water-and fat-soluble vitamins in pharmaceutical preparations by high-performance liquid chromatography coupled with diode array detection. Anal. Chim. Acta., 520 (1-2): 57-67.

21. Shabir, G.A. (2005) Step-by-step analytical methods validation and protocol in the quality system compliance industry. J. Valid. Technol., 10: 314-325.

22. FDA, Analytical Procedures and Methods Validation for Drugs and Biologics. (2015) Guidance for Industry, U. S. Department of Health and Human Services Food and Drug Administration Center for Drug Evaluation and Research (CDER), Center for Biologics Evaluation and Research (CBER), Pharmaceutical Quality.

23. Marson, B.M., Concentino, V., Junkert, A.M., Fachi, M.M., Vilhena, R.O. and Pontarolo, R. (2020) Validation of analytical methods in a pharmaceutical quality system: An overview focused on HPLC methods. Quimica Nova, 43(8): 1190-1203.

24. Rakuša, Ž. T., Grobin, A. and Roškar, R. (2021) A comprehensive approach for the simultaneous analysis of all main water-soluble vitamins in multivitamin preparations by a stability-indicating HPLC-DAD method. Food Chem., 337(4): 127768.

25. Langer, S. and Lodge, J.K. (2014) Determination of selected water-soluble vitamins using hydrophilic chromatography: A comparison of photodiode array, fluorescence, and coulometric detection, and validation in a breakfast cereal matrix. J. Chromatogr. B, 960(11): 73-81.

26. Santos, J., Mendiola, J.A., Oliveira, M.B.P., Ibáñez, E. and Herrero, M. (2012) Sequential determination of fat-and water-soluble vitamins in green leafy vegetables during storage. J. Chromatogr. A, 1261(43): 179-188.

27. Chen, Z., Chen, B. and Yao, S. (2006) High-performance liquid chromatography/electrospray ionization-mass spectrometry for simultaneous determination of taurine and 10 water-soluble vitamins in multivitamin tablets. Anal. Chim. Acta., 569(1-2): 169-175.

28. Vidović, S., Stojanović, B., Veljković, J., Pražić-Arsić, L., Roglić, G. and Manojlović, D. (2008) Simultaneous determination of some water-soluble vitamins and preservatives in multivitamin syrup by validated stability-indicating high-performance liquid chromatography method. $J$. Chromatogr. A, 1202(2): 155-162.

29. Jin, P., Xia, L., Li, Z., Che, N., Zou, D. and Hu, X. (2012) Rapid determination of thiamine, riboflavin, niacinamide, pantothenic acid, pyridoxine, folic acid and ascorbic acid in vitamins with minerals tablets by high-performance liquid chromatography with diode array detector. J. Pharm. Biomed. Anal., 70(12): 151-157. 